\title{
Towards building consensus: Revisiting key principles of CBPR within the First Nations/Aboriginal context
}

\author{
Pammla Petrucka $^{1}$, Sandra Bassendowski ${ }^{1}$, Deanna Bickford ${ }^{1}$, Elder Velma Goodfeather ${ }^{2}$ \\ ${ }^{1}$ College of Nursing (Regina Site), University of Saskatchewan, Regina, Canada \\ ${ }^{2}$ Standing Buffalo First Nation, Saskatchewan, Canada \\ Email: pammla.petrucka@usask.ca
}

Received 26 March 2012; revised 28 April 2012; accepted 3 May 2012

\begin{abstract}
Community based participatory research as a preferred approach to research with First Nations and Aboriginal communities has contributed to new terminologies, new methodologies, and new directions in research relationships. One of the ongoing challenges is to articulate and operationalize the principles for CBPR with these communities. This paper reflects on the nine principles articulated by LaVeaux and Christopher in the context of a long term community-academic research partnership at Standing Buffalo First Nations, Saskatchewan, Canada. Within this application, we begin to critique the various principles and to reframe these principles to increase their utility in informing community based research in the First Nations/Aboriginal context.
\end{abstract}

Keywords: Community Based Participatory Research; First Nations; Aboriginal; Research Principles

\section{INTRODUCTION}

The use of community based participatory research (CBPR) methods has become increasingly recognized as appropriate when working with Indigenous (i.e., First Nations/Aboriginal) populations as it is potentially empowering and inclusive for groups who have lacked voice [1-4]. Community-based research is collaboration between community groups and researchers for the purpose of creating new knowledge or understanding about a practical community issue in order to bring about change. Community-based research therefore is collaborative, participatory, empowering, systematic, and transformative. Such a model is focused on knowledge gathering as well as action to address pressing community issues [5-8]. CBPR highlights the centrality of the community in not only setting but operationalizing its research agenda. However, researchers selecting this methodological approach must be intimately aware of the context and concerns related to conducting research with
First Nations/Aboriginal peoples. These researchers are challenged by emerging trends, policies, and preferred futures of these communities to exercise increased control [9], self-determination [10], ethics frameworks [5], and equitable involvement [11] in all phases of the research process.

This paper will consider 9 principles outlined by LaVeaux and Christopher [12] for conducting CBPR with First Nations/Aboriginal communities. Following a brief review of these principles, a description of the context of a long-term research relationship with Standing Buffalo First Nation in Saskatchewan Canada will be provided. From this reflective process, a re-consideration of these nine principles will be posited with emphasis on their utility and potential modifications to better inform CBPR teams working within First Nations/Aboriginal contexts.

\section{THE PRINCIPLES: AN OVERVIEW}

LaVeaux and Christopher [12] considered the work of Israel et al. [2] which articulated eight key principles for conducting research using CBPR approaches. Although these latter authors recognized the applicability and importance of this work in the context of research with First Nations/Aboriginal people, through the work of LaVeaux and Christopher [12] nine additional principles specific to these groups were identified. Briefly these are described herein:

\subsection{Acknowledge Historical Experience with Research and Work to Overcome the Negative Image of Research}

This principle recognizes the very real issues of past research practices which were disrespectful, neglectful and exploitive of these peoples. In response, there has been an explosion First Nations/Aboriginal driven protocols, codes of ethics, and restrictive policies on research within these communities [9,13-15] in an effort to reframe and reintroduce research in a more culturally- 
balanced, trustworthy, and ethical manner.

\subsection{Recognize Tribal Sovereignty}

This principle recognizes existence, importance and preeminence of tribal governance models and jurisdictions within the research relationships [15-17]. Tribes have been the subjects of paternalistic institutional research practices for many years, with such approaches being displaced by efforts of self-determination $[5,9,18]$.

\subsection{Differentiate between Tribal and Community Membership}

Israel et al. [2] stressed the CBPR principle of seeing the community as the unit of identity, which is expanded to variable definitions of community by LaVeaux and Christopher [12]. These latter authors emphasize that, although similar experiences, values, and histories of colonization, residential schools, traditions, and tribal linkages bind First Nations/Aboriginal peoples together $[19,20]$, these relationships are further complicated by membership requirements and self-identification [21-24]. Hence researchers must work collaboratively towards respecting and aligning within these definitions and parameters to truly reflect the community unit.

\subsection{Understand Tribal Diversity and Its Implications}

First Nations and Aboriginal people are not a homogeneous group [17,25,26], hence researchers must undertake to pay attention to and embrace these elements of difference $[27,28]$. The key implication for researchers is that there is variability within and across groups so efforts must be made to be aware and inclusive, which can only be achieved through purposive and immersive efforts [23].

\subsection{Plan for Extended Timelines}

There is an imperative for researchers to invest time building relationships and trust throughout the course of the research. This goes beyond the iterative process described by Israel et al and extends to intensive and prolonged engagement with the community $[18,29]$. All of these are impacted by community event/ceremonies, people, and prior experiences with researchers; hence time commitment and engagement is the litmus test of a researcher's sincerity and integrity $[13,28,30]$.

\subsection{Recognize Key Gatekeepers}

The research must know and work closely with key individuals such as Elders and community leaders (formal and informal) $[17,31]$ for a number of reasons. These gatekeepers or knowledge holders are critical launchers and linkers at all stages of the project as well as for maintaining the research momentum at times of leadership transitions $[12,14,18]$. So the critical message within this principle is the need for acknowledgement and embedded-ness of co-learning and mutual regard with these key stakeholders and knowledge holders throughout the research [30,32].

\subsection{Prepare for Leadership Turnover}

In order to address the various processes and conditions for the changes in leadership and to limit disruption to research projects, there is an increased presence and recommendation for formal research partnership documents $[5,13,18]$. Such documents are not binding, but do articulate intentions, roles, and commitments, thereby contributing to continuity.

\subsection{Interpret Data within the Cultural Context}

It is critical that community members are included in this phase of the research process in order to embed cultural belief systems, and ways of knowing as well as to strengthen capacity of the community in terms of future research $[5,33]$. Through inclusivity in data interpretation, dissemination of information will be guided, reflexivity of the community's voice will be entrenched, and findings will be available in community accessible formats [5,34].

\subsection{Utilize Indigenous Ways of Knowing}

This principle focuses on the unique beliefs and values which, when incorporated into CBPR research projects, will enrich and more correctly reflects Indigenous knowledges and understandings [35-38]. A key strategy towards achievement of this principle lies in the use of Indigenous methodologies [12] in research projects which are more apt to be engaging and empowering for the communities.

\section{THE PROJECT: STANDING BUFFALO FIRST NATION CBPR EXEMPLAR}

Over nearly eight years, an innovative, community-engaged program of research has evolved through engagement between Standing Buffalo First Nation (SBFN), First Nations University of Canada, and University of Saskatchewan [39-41]. The program's inception was rooted in the goals for cultural competence in health care and culturally informed evidence for health. Through a series of community meetings and sharing circles, the inter-sectoral, inter-agency team co-created a shared vision and baseline knowledge on the topic of "Okanku Duta Amani-Paths to Living Well" for on-reserve 
members of SBFN. This topic holds significance and relevance to community members, specifically, and First Nations/Aboriginal peoples, generally, as it challenges current linear approaches and seeks to build knowledge from a First Nations/Aboriginal lens.

Although the lead project was a photovoice initiative with youth, the entire community has been engaged in the research and supporting their "Photovoice Kids". Through open community meetings, celebratory feasts, briefings, and face to face meetings, it has been possible to build consensus on the scope of involvements, to guide research activities, and to identify opportunities for knowledge translation and dissemination. A research team of community (i.e., Elders, residents), local authorities (i.e., Chief, Band Councillors), professional (i.e., education and health care staff), and academic members have jointly addressed all aspects of the research. This inclusive and intentional approach, which was established early in the process, and has been revisited at strategic points (i.e., after the pilot study, after the photovoice phase, etc.) has been foundational to the success and sustainability of the CBPR experience at SBFN. Most significantly, we learned that advice and guidance of the Elders are critical to development of the partnerships and research process and, ultimately, to sustainability of the effort.

From the logistic lens, two key learnings occurred. The first was that working in a community-based partnership takes additional time and resources which must be planned for in timelines and organization of the research. The additional time was essential for learning, trust, and respect as well as building the team. A second key learning was that the use of CBPR approach was appropriate and facilitative allowing the strengths of each member of the research team to be fully utilized and for capacity building opportunities to be identified and addressed.

Together, members of the team moved positively to support each other, the participants, and the community in improving the understanding of Pathways to Living Well. Through this process, three key promising practices arose. First, there is an imperative to commit to a longstanding relationship and engagement with the community. Standing Buffalo First Nation has privileged the academic team with open dialogue and a level of trust that can only be gained through a presence and commitment from all team members. As we have recently embarked on a new research stream, the re-negotiation and re-affirmation of the commitment was found to be straightforward and seamless. Second, the process must be inclusive, transparent, active, and community specific. The team has recognized the need to engage a wide range of community members, decision makers, participants, professionals, staff, and academics in "active processes and interactive engagement and exchange" [42]. We note that this was a key enabler for the team to be open and responsive to every opportunity brought forward and allowed us to maximize for innovation and change. Third, flexibility and responsiveness in a community based partnership is essential to innovation and collaboration. In this program the suggestions and potential directions are shared openly resulting in significant changes from the original research plan in order to be community relevant.

An evolving learning - one which we as a team are still struggling to fully understand - is the need for strategies for traditional knowledge translation, shared decision making, and research utilization. Throughout the course of this research the team recognized that embedding knowledge translation activities appropriate to diverse and non-academic audiences is critical. Kitson [43] states that “... successful translation of new knowledge into any system is a function of the level of local autonomy experienced by individuals, teams and the [community] involved in the change". This imperative requires continuous reflection and emphasis on the importance of linking past to present to future, traditional to Western, and knowing to showing. Throughout, the strengths of the community partners in highlighting cultural and social aspects were evident; while other team members contributed by querying cultural meanings and seeking clarification of appropriate knowledge translation aspects. There was significant respect for the knowledge shared and all final products reflected this mutual regard and honoring of traditional ways of knowing.

\section{THE POSSIBILITIES: A REFLECTION ON THE PRINCIPLES IN PRACTICE}

As we reflected retrospectively upon the principles articulated by LaVeaux and Christopher and our CBPR experience in a First Nations/Aboriginal context, we recognized the potential of these ideas to inform research and guide those researchers considering or entering into this amazing and challenging context. We found that each of these principles resonated with our experiences with the SBFN community and often validated our experiences. The team found the individual descriptors of the principles were sufficient in creating a common understanding of background and intention. However, as we attempted to increase our understanding and applications of the principles, we found ourselves questioning the essence and necessity of certain principles as they were articulated. As a result, we tentatively reframed and reconstituted some of the principles in order to increase utility and applicability in our context. The following reflects what is seen as the possibilities to contribute to 
the refining of these principles into a working model.

Our team recognized the first four principles as the foundational work of the incoming researcher/research team-essentially doing the "homework" necessary before entering into the community. Although inclusion of the community is implicit, it would be meritous to seek examples and promising practices on how this is made explicit and practical. Further, we envisioned the first four principles as being about "Knowing the Community: Its people and its context" and recommend collapsing these under this heading as a single guiding principle. With minor wordsmithing, these principles reflect sound research skills necessary when working with any vulnerable, at-risk or potentially marginalized population. In our program of research, it has been important to "Know our Community" on a number of different levels and we have taken measures such as a study tour to the Smithsonian Institute, language embedded-ness through the Elders, and consistent liaising and clarifying to build understanding of the context. Our response to these principles would be to reconsider their independent listing and embrace them as a foundational principle as "Knowing the Community".

In terms of principle \#5, we acknowledge the need to consider timelines, but consider this to be an organizational (logistical) issue rather than a principle. In our work, time is seen as a resource which is to be wisely used by all team members. Although it is critical to be aware of the issues and possible challenges to time, this is not unique to First Nations/Aboriginal contexts, but exists across most CBPR involvements. Hence, our recommendation would be to include this in advisories on planning and conducting research with communities rather than as a principle or rule.

Our team considered principles \#6 and 7 as highly inter-related. Together, for us, they represented the continuum from entrée to exit (inclusive of sustainability). In our research program, we have found that inclusiveness, early and continuous involvement, and openness have enabled us in "Becoming and Remaining Relevant". It would be our suggestion that the original authors consider the possibility of uniting these two principles and under this proposed umbrella principle, provide guidance to explore opportunities for continuous engagement, embeddedness, and appropriate exit/transition/sustainability strategies.

In terms of the final two principles our team was both appreciative and supportive of their inclusion and intention. In our work we found that these were iterative and co-learned aspects of the research which made the efforts dynamic and sustainable. These principles further ground the research team in considering the importance of continually seeking ways to validate or approach the research in an innovative, culturally informed manner.
From our perspective it would be more meaningful to move the final principle-utilizing Indigenous ways of knowing - to the top of the list as it honours and clearly focuses the research within Indigenous ways of knowing.

\section{ONE WAY FORWARD}

In seeking opportunities to enhance and advance CBPR within First Nations/Aboriginal contexts it is important to recognize and strive for excellence. The work of LaVeaux and Christopher is an important step in evolving the principles of CBPR to achieve this end. Our team agreed unequivocally with the comment that "it is necessary to go beyond the CBPR recommendations" [12]. However, in reflection on the nine principles advanced by these authors, in the context of our long-term research involvement with a First Nations community, our research team was able to variably accept, adapt, and reject. Our interpretations and recommendations are solely brought for discussion debate to enrich the understanding of CBPR with this unique population and continue to be "bridge-builders for future research among [First Nations/Aboriginal] communities” [12].

\section{ACKNOWLEDGEMENTS}

This research was funded by the Canadian Institutes of Health Research-Institute of Aboriginal Peoples Health.

\section{REFERENCES}

[1] Etowa, J., Thomas Bernard, W., Oyinsan, B. and Clow, B. (2007) Participatory action research: An approach for improving Black women's health in rural and remote communities. Journal of Transcultural Nursing, 18, 349357. doi:10.1177/1043659607305195

[2] Israel, B., Schulz, A., Parker, E. and Becker, A. (1998) Review of community-based research: Assessing partnership approaches to improve public health. Annual Review of Public Health, 19, 173-202. doi:10.1146/annurev.publhealth.19.1.173

[3] Minkler, M. and Wallerstein, N. (2008) Community based participatory research for health: Process to outcomes. 2nd Edition, Jossey Bass, San Francisco.

[4] Westfall, J., VanVorst, R.F., Main, D.S. and Hebert, C. (2006) Community-based participatory research in practice-based research networks. Annals of Family Medicine, 4, 8-14. doi:10.1370/afm.511

[5] Canadian Institutes of Health Research, Natural Sciences and Engineering Research Council of Canada, and Social Sciences and Humanities Research Council of Canada (TCPS) (2010) Tri-Council policy statement: Ethical conduct for research involving humans. http://www.pre.ethics.gc.ca

[6] Castleden, H., Garvin, T. and Huu-ay-aht First Nation. (2008) Modifying photovoice for community-based par- 
ticipatory Indigenous research. Social Science and Medicine, 66, 1393-1405.

doi:10.1016/j.socscimed.2007.11.030

[7] Labonte, R. (2004) Community, community development, and the forming of authentic partnerships: Some critical reflections. In: Minkler, M. Ed., Community Organizing and Community Building for Health, Rutgers University Press, New Brunswick.

[8] Moffitt, P. and Robinson-Vollman, A. (2004) Photovoice: Picturing the health of aboriginal women in a remote northern community. Canadian Journal of Nursing Research, 36, 189-201.

[9] Schnarch, B. (2004) Ownership, control, access, and possession (OCAP) or self-determination applied to research: A critical analysis of contemporary First Nations research and some options for First Nations communities. Journal of Aboriginal Health, 1, 80-97.

[10] First Nations Centre (2007) OCAP: Ownership, control, access and possession. Sanctioned by the First Nations Information Governance Committee, Assembly of First Nations. National Aboriginal Health Organization, Ottawa.

[11] Interagency Advisory Panel on Research Ethics (2008) Research involving Aboriginal peoples. http://www.pre.ethics.gc.ca/eng/index

[12] LaVeaux, D. and Christopher, S. (2009) Contextualizing CBPR: Key Principles of CBPR meet the Indigenous research context. Pimatisiwin, 7, 1-5.

[13] Christopher S. (2005) Recommendations for conducting successful research with Native Americans. Journal of Cancer Education, 20, 47-51. doi:10.1207/s15430154jce2001s_11

[14] Letiecq, B.L. and Bailey, S.J. (2004) Evaluating from the outside: Conducting cross-cultural evaluation research on an American Indian reservation. Evaluation Review, 28, 342-357. doi:10.1177/0193841X04265185

[15] Strickland, C.J. (2006) Challenges in community-based participatory research implementation: Experiences in cancer prevention with Pacific Northwest American Indian Tribes. Cancer Control: Journal of the Moffitt Cancer Center, 13, 230-236

[16] Chino, M. and DeBruyn, L. (2006) Building true capacity: Indigenous models for Indigenous communities. American Journal of Public Health, 96, 596-599. doi:10.2105/AJPH.2004.053801

[17] Martin-Hill, D. and Soucy, D. (2005) Ganono'se'n e yo'gwilode'-Ethical Guidelines for Aboriginal Research Elders and Healers Roundtable. Commissioned by the Aboriginal Ethics Policy Development Project and supported by the Ethics Office of the Canadian Institutes of Health Research, Government of Canada, Ottawa.

[18] Burhansstipanov, L., Christopher, S. and Schumacher, A. (2005) Lessons learned from community-based participatory research in Indian country. Cancer, Culture and Literacy, 70-76.

[19] Belcourt-Dittloff, A. and Stewart, J. (2000) Historical racism: Implications for Native Americans. American
Psychologist, 1166-1167. doi:10.1037/0003-066X.55.10.1166

[20] Truth and Reconciliation Commission of Canada (TRCC) (2012) Truth and Reconciliation Commission of Canada: Interim report. TRCC, Winnipeg.

[21] Norton, I.M. and Manson, S.M. (1996) Research in American Indian and Alaska Native communities: Navigating the cultural universe of values and process. Journal of Consulting and Clinical Psychology, 64, 856-860. doi:10.1037/0022-006X.64.5.856

[22] Statistics Canada (2011) 2006 Census: Aboriginal Peoples in Canada in 2006: Inuit, Métis and First Nations, 2006 Census: Definitions and notes. http://www12.statcan.ca/census-recensement/2006/as-sa/ 97-558/note-eng.cfm

[23] Wax, M.L. (1991) The ethics of research in American Indian communities. American Indian Quarterly, 15, 431456. doi:10.2307/1185363

[24] Wallerstein, N.B. and Duran, B. (2006) Using community-based participatory research to address health disparities. Health Promotion Practice, 7, 312-323. doi:10.1177/1524839906289376

[25] Voyageur, C.J. and Calliou, B. (2000) Various shades of red: Diversity within Canada's Indigenous community London Journal of Canadian Studies, 16, 109-124.

[26] Health Canada (2009) Our voices: First Nations, Métis, and Inuit gender based analysis toolkit. British Columbia Centre for Excellence on Women's Health, Vancouver.

[27] Christopher, S., Knows His Gun McCormick, A., Smith, A. and Christopher, J.C. (2005) Development of an interviewer training manual for a cervix health project on the Apsaalooke reservation. Health Promotion Practice, 6, 414-422. doi:10.1177/1524839904268521

[28] Crazy Bull, C. (1997) A Native conversation about research and scholarship. Tribal College: Journal of American Indian Higher Education, 8, 17-23.

[29] Christopher, S., Smith, A. and Knows His Gun McCormick, A. (2005) Participatory development of a cervical health brochure for Apsaalooke women. Journal of Cancer Education, 20, 173-176. doi:10.1207/s15430154jce2003_12

[30] Beardi, G. and Donnelly, S. (1999) Rural participatory research in Alaska: The case of Tanakon Village. Journal of Rural Studies, 15, 171-178. doi:10.1016/S0743-0167(98)00053-9

[31] Ellerby, J.H. (2001) Working with Aboriginal elders: An introductory handbook for institution-based and health care professionals based on the teachings of Aboriginal elders and cultural teachers. Native Studies Press, University of Manitoba, Winnipeg.

[32] Strickland, C.J. (2006) Challenges in community-based participatory research implementation: Experiences in cancer prevention with Pacific Northwest American Indian Tribes. Cancer Control: Journal of the Moffitt Cancer Center, 13, 230-236.

[33] Mihesuah, D.A. (1993) Suggested guidelines for institutions with scholars who conduct research on American 
Indians. American Indian Culture and Research Journal, 17, 131-139.

[34] Smith, A., Christopher, S. and Knows His Gun McCormick, A. (2004) Development and implementation of a culturally sensitive cervical health survey: A communitybased participatory approach. Women \& Health, 40, 67-86. doi:10.1300/J013v40n02 05

[35] Archibald, J. (2001) Sharing Aboriginal knowledge and Aboriginal ways of knowing. Canadian Journal of Native Education, 25, 1-18.

[36] Battiste, M., Bell, L. and Findlay, L.M. (2002) Decolonizing education in Canadian universities: An interdisciplinary, international, indigenous research project. Canadian Journal of Native Education, 26, 82-95.

[37] Bruyere, G. Traditional knowledge. University of the Artic: Contemporary issues in the Circumpolar World 2. http://www.uartic.org/bcs/BCS332/module_4.pdf

[38] Crowshoe, C. (2005) Sacred ways of life: Traditional knowledge. Prepared for First Nations Centre National Aboriginal Health Organization.

http://www.naho.ca/firstnations/english/documents/FNCTraditionalKnowledgeToolkit-Eng.pdf

[39] Bassendowski, S., Petrucka, P., Smadu, M., Redman, R. and Bourassa, C. (2006) Relationship building for research: The South Saskatchewan urban aboriginal health coalition. Contemporary Nurse, 22, 267-277. doi:10.5172/conu.2006.22.2.267

[40] Petrucka, P., Bassendowski, S. and Bourassa, C. (2007) Seeking paths to culturally competent health care: Learning from two Saskatchewan Aboriginal communities. Canadian Journal of Nursing Research, 39, 166-182.

[41] Racine, L. and Petrucka, P. (2011) Enhancing decolonization and knowledge transfer in nursing research with non-Western populations: Examining the congruence between primary health care and postcolonial feminist approaches. Nursing Inquiry, 18, 12-20. doi:10.1111/j.1440-1800.2010.00504.X

[42] Lavis, J.N., Robertson, D., Woodside, J.M., McLeod, C.B. and Abelson, J. (2003) How can research organizations more effectively transfer research knowledge to decision makers? Milbank Quarterly, 81, 221-248. doi:10.1111/1468-0009.t01-1-00052

[43] Kitson, A.L. (2009) The need for systems change: Reflections on knowledge translation and organizational change. Journal of Advanced Nursing, 65, 217-228. doi:10.1111/j.1365-2648.2008.04864.x 